$\xi=-$ 国

\title{
Material Performance of Nickel Ions Adsorption by Larix Sibirica Needles
}

\author{
Tatiana R. Denisova ${ }^{1}$, Damir A. Kharlyamov ${ }^{1}$, Rumia Z. Galimova ${ }^{2}$, Ildar G. Shaikhiev ${ }^{2}$, Svetlana V. Sadykova ${ }^{2}$ \\ 1 Kazan Federal University \\ ${ }^{2}$ Kazan National Research Technological University \\ *Corresponding author E-mail: timiryanova.tanya@yandex.ru
}

\begin{abstract}
Adsorption of ions of nickel on alternative sorption material - needles of Siberian larch (Larix sibirica) is investigated at temperatures of 20,30 and $40{ }^{\circ} \mathrm{C}$. The maximum sorption capacities of needles of Larix sibirica in relation to ions of nickel (II) at temperatures of 20 are determined ${ }^{\circ} \mathrm{C}, 30^{\circ} \mathrm{C}, 40^{\circ} \mathrm{C}$ which made $0,80 \mathrm{mmol} / \mathrm{g}(47,2 \mathrm{mg} / \mathrm{g}), 0,87 \mathrm{mmol} / \mathrm{g}(51,3 \mathrm{mg} / \mathrm{g})$ and $0,92 \mathrm{mmol} / \mathrm{g}(54,3 \mathrm{mg} / \mathrm{g}) \mathrm{respectively}$. Isotherms of adsorption are received and shortchanged with use of models of Langmuir, Friendlich, Temkin and Dubinin-Radushkevich. It is defined that process of adsorption of ions of $\mathrm{Ni}^{2+}$ at a temperature of 20 the ${ }^{\circ} \mathrm{C}$ is best of all described by Friendlich's model $(\mathrm{R} 2=$ 0,983), and at temperatures of $30^{\circ} \mathrm{C}$ and $40^{\circ} \mathrm{C}$ - the Langmuir model ( $\mathrm{R} 2=0,995$ and 0,996 respectively). By the carried-out calculations it is defined that process of adsorption of ions of $\mathrm{Ni}^{2+}$ needles of Larix sibirica treat processes of physical adsorption as values of energy of adsorption have size less than $8 \mathrm{~kJ} / \mathrm{mol}$, and values of energy of Gibbs demonstrate spontaneous course of physical adsorption. Processing of kinetic dependences of processes of adsorption of ions of nickel (II) Larix sibirica needles at three temperatures within diffusive model defined the limiting stages of processes - the mixed diffusion.
\end{abstract}

Keywords: : sorption material, needles of a larch Siberian, ions of nickel, adsorption isotherm, water purification.

\section{Introduction}

In the field of cleaning natural and sewage the new innovative direction - use as reagents of waste of industrial and agricultural production and natural mineral environments appeared now. Use of the called reagents is especially relevant for removal from water environments of the ions of heavy metals (IHM). The last, as a rule, are present at water objects in the dissolved state that does the majority of physical and chemical ways of cleaning inefficient, and use of reagent chemical cleaning, especially in natural reservoirs, impossible. Use of sorption technologies can be an exit from the situation. Application of traditional sorbents - absorbent carbon is limited to their high cost and low sorption capacity in relation to many ITM.

Due to the above, as sorption materials renewable cellulose containing waste from processing of agricultural raw materials is of special interest for extraction of ITM [1-10]. The separate position in a case in point is made by waste from processing of wood biomass (sawdust, shavings, and spill) and components of trees (leaves, fruits, needles, cones, etc.). It is shown that sawdust of wood [11-15] and bark [16, 17], leaves [18, 19], the crushed fruits [20, 21], seeds of fruits [22], cones [23] effectively delete ITM from water solutions.

Leaves and needles of trees of various types are of special interest. Advantage of foliage is that the last have big annually renewable biomass, and needles - big in comparison in foliage the area in terms of unit of mass. Use of needles of trees of coniferous types as sorption materials for extraction of pollutant including ITM, is shown, in particular, in works [24-26]. The needles of trees of the type Larix are of special interest in view of the fact that they as well as trees of sheet types in the conditions of the Russian Federation dump needles before the winter period.

On the basis of the above, sorption of ions of Ni (II) with use as sorption material of needles of Siberian larch (Larix sibirica) was investigated. In the world literature there are messages about a research of sorption of ions $\mathrm{Cr}(\mathrm{III})$ and $\mathrm{Cr}(\mathrm{VI})$ needles of larch pre-Jurassic Lárix gmélinii [27] and thin-scaled larch (Larix leptolepis) [28].

\section{Methods}

In experiments the dry fallen-down needles of a season of 2016 were used. Originally determined the sizes of the studied sorption material. For this purpose 100 needles were randomly selected and by means of a ruler and a micrometer their length and thickness were measured. By the taken measurements and the corresponding mathematical calculations it is defined that needles have average value of length of $30,5 \mathrm{~mm}$, thickness - 560 microns. Further some physical parameters specified in table 1 were defined.

In the subsequent isotherms of sorption of ions of Ni were under construction $^{2+}$ needles of Larix sibirica (table 1) at temperatures of $200 \mathrm{C}, 300 \mathrm{C}$ and $400 \mathrm{C}$. For this purpose in flat-bottomed flasks of $250 \mathrm{~cm}^{3}$ hinge plates of sorption materials on $1 \mathrm{~g}$ were located with weight. Then in flasks about $100 \mathrm{~cm}$ were filled in ${ }^{3}$ solutions containing Ni ions ${ }^{2+}$ in concentration of $10-1500 \mathrm{mg} / \mathrm{dm}^{3}$.

Table 1:. Physical properties of Larix sibirica needles.

\begin{tabular}{|l|c|}
\hline \multicolumn{1}{|c|}{ Property } & Value \\
\hline Bulk density $\rho, \mathrm{g} / \mathrm{cm}^{3}$ & 0,06 \\
\hline Moisture $\mathrm{W}, \%$ & 11,25 \\
\hline Ash content $\mathrm{A}_{\mathrm{c}}, \%$ & 0,50 \\
\hline Buoyancy $\mathrm{P}, \%$ & 56,44 \\
\hline
\end{tabular}


As the connections containing $\mathrm{Ni}$ ions in the structure ${ }^{2+}$, for preparation of model solutions $\mathrm{NiSO}_{4} \cdot 7 \mathrm{H}_{2} \mathrm{O}$ were used. Hinge plates of sulfate of nickel undertook taking into account crystallizational water. Flasks with the hinge plates and the corresponding solutions which are in them were densely closed by traffic jams and vigorously stirred up within 5 hours. Then needles were filtered and in filtrates equilibrium concentration of ions of $\mathrm{Ni}$ (II) were defined by a photometric method [28].

On the basis of the obtained experimental data, the sorption capacity of needles of a larch (A) on a formula is calculated:

And $=\left(\mathrm{Cs}_{\mathrm{s}}-\mathrm{Se}\right) \cdot \mathrm{V} / \mathrm{m} \quad$ (1)

where And - sorption capacity on ITM $(\mathrm{mmol} / \mathrm{g})$, Cs - initial concentration of ITM $(\mathrm{mmol} / \mathrm{dm} 3)$, se - concentration of ITM after sorption $(\mathrm{mmol} / \mathrm{dm} 3)$,

V - solution volume (dm3), m - weight sorption swore ().

\section{Results and Discussion}

Isotherms of sorption of ions of $\mathrm{Ni}^{2+}$ on Larix sibirica needles at various temperatures are presented in the figure 1.

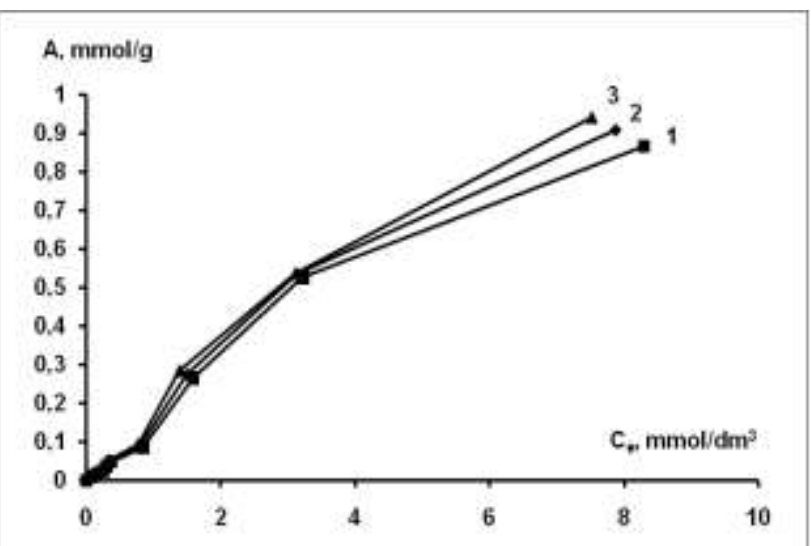

Fig. 1:. Isotherms for adsorption of $\mathrm{Ni}^{2+}$ ions by Larix sibirica needles at different temperatures: $1-20^{\circ} \mathrm{C}, 2-30^{\circ} \mathrm{C}, 3-40^{\circ} \mathrm{C}$.

According to the figure 1 it is visible that the received isotherms belong to isotherms of the I type of classification of BDDT or the L type according to Gils's classification and describe monomolecular adsorption of ions of $\mathrm{Ni}^{2+}$ on needles of a larch [29]. The maximum sorption capacities of needles of Larix sibirica in relation to ions of nickel (II) at temperatures of 20 are determined ${ }^{\circ} \mathrm{C}$, $30^{\circ} \mathrm{C}, 40^{\circ} \mathrm{C}$ which made $0,80 \mathrm{mmol} / \mathrm{g}(47,2 \mathrm{mg} / \mathrm{g}), 0,87 \mathrm{mmol} / \mathrm{g}$ $(51,3 \mathrm{mg} / \mathrm{g})$ and $0,92 \mathrm{mmol} / \mathrm{g}(54,3 \mathrm{mg} / \mathrm{g})$ respectively.

Due to the aforesaid, with a research objective of course of mechanisms of processes of adsorption, the received isotherms are processed within four monomolecular models of adsorption: Langmuir, Friendlich, Dubinin-Radushkevich and Temkin [29], according to the equations:

Langmuir $\frac{1}{\mathrm{~A}}=\frac{1}{\mathrm{~A}_{\infty}}+\frac{1}{\mathrm{~K}_{\mathrm{L}} \cdot \mathrm{A}_{\infty} \bullet \mathrm{C}_{\mathrm{e}}}$

Friendlich $\log \mathrm{A}={ }_{\log \mathrm{KF}}+{ }_{\mathrm{n} \log \mathrm{Ce}}$

$$
\underset{\text { Temkina }}{\mathrm{A}}=\frac{\mathrm{R} \cdot \mathrm{T}}{\mathrm{b}_{\mathrm{TE}}} \cdot \ln \mathrm{a}_{\mathrm{TE}}+\frac{\mathrm{R} \cdot \mathrm{T}}{\mathrm{b}_{\mathrm{TE}}} \cdot \ln \mathrm{C}_{\mathrm{e}}
$$$$
\text { Dubinina-Radushkevich }
$$$$
\ln A=\ln A_{\infty}-\left(\frac{R \cdot T}{E}\right)^{2} \cdot\left(\ln \frac{C_{s}}{C_{e}}\right)^{2}
$$

As criterion of compliance the approximation coefficient was used (R2), which value equal 1 , means that full compliance of process of this model of sorption is observed; the value of coefficient of approximation is closer to unit, the better this model describes the studied process.
Results of processing of isotherms of adsorption of ions of nickel (II) Larix sibirica needles at temperatures of $20^{\circ} \mathrm{C}, 30^{\circ} \mathrm{C}, 40^{\circ} \mathrm{C}$ within monomolecular models: Langmuir, Friendlich, DubininRadushkevich, Temkin are presented in table 2.

Table 2:. Mathematical treatment of isotherms for adsorption of $\mathrm{Ni}^{2+}$ ions by Larix sibirica needles.

\begin{tabular}{|c|c|c|c|}
\hline Adsorption model & \multicolumn{3}{|c|}{ Temperature } \\
\cline { 2 - 4 } & $20^{\circ} \mathrm{C}$ & $30^{\circ} \mathrm{C}$ & $40^{\circ} \mathrm{C}$ \\
\hline Langmuir & $\mathrm{y}=6,785 \mathrm{x}+$ & $\mathbf{y}=\mathbf{7 , 4 3 7} \mathbf{4 3}+$ & $\mathbf{y}=\mathbf{6 , 8 8 2 x}+$ \\
& 3,520 & $\mathbf{0 , 3 1 5}$ & $\mathbf{0 , 0 4 3}$ \\
& $\mathrm{R}^{2}=0,975$ & $\mathbf{R}^{2}=\mathbf{0 , 9 9 5}$ & $\mathbf{R}^{\mathbf{2}=\mathbf{0 , 9 9 6}}$ \\
\hline Freindlich & $\mathbf{y}=\mathbf{1 , 0 0 1 x}-$ & $\mathrm{y}=1,016 \mathrm{x}-$ & $\mathrm{y}=1,009 \mathrm{x}-$ \\
& $\mathbf{0 , 8 9 8}$ & 0,859 & 0,825 \\
& $\mathbf{R}^{\mathbf{2}=\mathbf{0 , 9 8 3}}$ & $\mathrm{R}^{2}=0,987$ & $\mathrm{R}^{2}=0,988$ \\
\hline Dubinin- & $\mathrm{y}=-3 \mathrm{E}-08 \mathrm{x}-$ & $\mathrm{y}=-3 \mathrm{E}-08 \mathrm{x}-$ & $\mathrm{y}=-3 \mathrm{E}-08 \mathrm{x}-$ \\
Radushkevich & 0,653 & 0,654 & 0,638 \\
& $\mathrm{R}^{2}=0,936$ & $\mathrm{R}^{2}=0,930$ & $\mathrm{R}^{2}=0,929$ \\
\hline Temkin & $\mathrm{y}=0,176 \mathrm{x}-$ & $\mathrm{y}=0,185 \mathrm{x}-$ & $\mathrm{y}=0,190 \mathrm{x}-$ \\
& 0,420 & 0,438 & 0,440 \\
& $\mathrm{R}^{2}=0,816$ & $\mathrm{R}^{2}=0,825$ & $\mathrm{R}^{2}=0,825$ \\
\hline
\end{tabular}

According to table 2 follows that at increase in temperature distribution of the active centers with identical values of sorption energy on the surface of material becomes more uniform that is caused by increase in coefficients of approximation of the Langmuir model.

Thermodynamic constants: sorption energy (E), Gibbs's $(\Delta \mathrm{G})$ energy, enthalpy $(\Delta H)$ and entropy $(\Delta S)$ of processes of sorption of ions of $\mathrm{Ni}^{2+}$ Larix sibirica needles at temperatures of $20^{\circ} \mathrm{C}$, $30^{\circ} \mathrm{C}, 40^{\circ} \mathrm{C}$ are calculated for the purpose of definition of the nature of processes of sorption (physical or chemical) on formulas 3-6 [29] and presented in table 3.

$\Delta \mathrm{G}=-\mathrm{R} \cdot \mathrm{T} \cdot \operatorname{lnKL}$,

(3)

$\mathrm{E}=(-2 \beta)^{-1 / 2}$,

(4)

$\Delta \mathrm{H}=\mathrm{R} \cdot(\mathrm{T} 2-\mathrm{T} 1) /\left({ }_{\mathrm{T} 2} \bullet \mathrm{T}_{1}\right) \cdot \ln (\mathrm{KL} 2 / \mathrm{KL} 1)$,

(5)

$\Delta \mathrm{S}=(\Delta \mathrm{H}-\Delta \mathrm{G}) / \mathrm{T}$,

(6)

where $\beta$ - Dubinin-Radushkevich's constant.

Table 3:. Thermodynamical constants of adsorption processes of $\mathrm{Ni}^{2+}$ ions by Larix sibirica needles.

\begin{tabular}{|c|c|c|c|c|}
\hline Temperature, ${ }^{\circ} \mathrm{C}$ & $\begin{array}{c}\mathrm{E}, \\
\mathrm{kJ} / \mathrm{mol}\end{array}$ & $\begin{array}{c}\Delta \mathrm{G}, \\
\mathrm{kJ} / \mathrm{mol}\end{array}$ & $\begin{array}{c}\Delta \mathrm{H}, \\
\mathrm{kJ} / \mathrm{mol}\end{array}$ & $\begin{array}{c}\Delta \mathrm{S}, \mathrm{J} /(\mathrm{mol} \cdot \\
\mathrm{K})\end{array}$ \\
\hline 20 & 4,082 & $-1,626$ & \multirow{2}{*}{8,023} & \multirow{2}{*}{32,93} \\
\hline 30 & 4,082 & $-7,832$ & & \\
\hline 40 & 4,082 & $-12,575$ & & \\
\cline { 1 - 3 } & \multicolumn{3}{|l}{}
\end{tabular}

According to table 3 it is visible that processes of adsorption of ions of $\mathrm{Ni}^{2+}$ Larix sibirica needles at all three temperatures treat processes of physical adsorption as values of energy of adsorption less than $8 \mathrm{~kJ} / \mathrm{mol}$ and values of an enthalpy less than $100 \mathrm{~kJ} / \mathrm{mol}$, and values of energy of Gibbs in the range from-20 to $0 \mathrm{~kJ} / \mathrm{mol}$ speak about spontaneous course of physical adsorption [29].

At the following stage the kinetics of processes of adsorption of ions of nickel (II) by Larix sibirica needles on model solutions of $0,1 \mathrm{dm}$ is studied ${ }^{3}$, with initial concentration of ions of nickel (II) of $1000 \mathrm{mg} / \mathrm{dm}^{3}$, time of sorption from 0 to $180 \mathrm{~min}$. and dosage of sorption material of $1 \mathrm{~g}$. Kinetic dependences of processes of sorption of ions of nickel (II) are constructed by Larix sibirica needles at temperatures of $20^{\circ} \mathrm{C}, 30^{\circ} \mathrm{C}, 40^{\circ} \mathrm{C}$ (figure 2). 


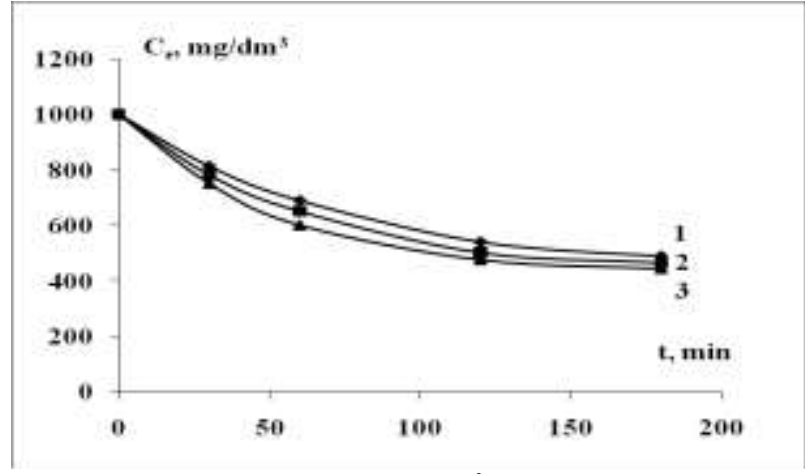

Fig. 2:. Kinetic curves for adsorption of $\mathrm{Ni}^{2+}$ ions by Larix sibirica needles at different temperatures: $1-20^{\circ} \mathrm{C}, 2-30^{\circ} \mathrm{C}, 3-40^{\circ} \mathrm{C}$.

As a rule, processes of physical adsorption are described with use of diffusive model which considers a contribution external (formula 7) and internal diffusion (formula 8) in adsorption process course. Biot's criterion calculated by a formula 9 in the range from 0 to 1 indicates that the limiting stage of process of adsorption is external diffusion, that is process of diffusion of an adsorbate in solution to the surface of adsorbent, at values of coefficient of Biot more than 20 the stage of internal diffusion, that is diffusion of an adsorbate in an adsorbent time is limiting, and at values of coefficient of Biot from 1 to 20 - the mixed diffusion, that is in process of adsorption makes an identical contribution both process external, and process of internal diffusion.

$$
D_{\text {вн }}=\frac{r_{0} \cdot \delta \cdot \gamma \cdot \mathrm{A}}{3 \cdot \mathrm{Ce}}
$$

$$
{ }_{D i}={ }_{B t} \cdot r 2 /\left(\pi^{2} \cdot t\right) \text {, }
$$

$$
B i=\frac{D_{\dot{B H}} r}{D_{i} \cdot \delta \cdot K_{p}},
$$

where ${ }_{D v n}$ - coefficient of external diffusion, ${ }_{r 0}$ - the radius of particles of a sorbent $(\mathrm{cm})$,

$\delta$ - solution film thickness around granules of a sorbent $(\mathrm{cm}), \gamma$ some size, a constant for these conditions, A - the sorption capacity $(\mathrm{mmol} / \mathrm{g}), \mathrm{se}$ - equilibrium concentration of sorbate in solution $(\mathrm{mmol} / \mathrm{cm} 3)$,

${ }_{D i}$ - coefficient of internal diffusion $(\mathrm{cm} 2 / \mathrm{c}){ }_{B t}$ - criterion of a homochromousness of Fourier, $r$ - the radius of grain of a sorbent (cm), $t$ - time (c), ${ }_{B i}$ - Biot's coefficient,

${ }_{K p}$ - the distribution coefficient determined by the equation: ${ }_{K p}=$ And / Ce.

Kinetic dependences of processes of adsorption of ions of nickel (II) at three temperatures are processed by Larix sibirica needles within diffusive model of adsorption, Biot's coefficients presented in table 4 are calculated.

Table 4:. Values of Bio ratio for adsorption of $\mathrm{Ni}^{2+}$ ions by Larix sibirica needles at different temperatures.

\begin{tabular}{|c|c|c|c|c|c|}
\hline \multirow{2}{*}{ Temperature } & \multicolumn{5}{|c|}{ Time, min } \\
\cline { 2 - 6 } & 0 & 30 & 60 & 120 & 180 \\
\hline $20^{\circ} \mathrm{C}$ & - & 8,91 & 6,57 & 1,83 & - \\
\hline $30^{\circ} \mathrm{C}$ & - & 8,89 & 6,37 & 1,74 & - \\
\hline $40^{\circ} \mathrm{C}$ & - & 7,84 & 5,29 & 1,70 & - \\
\hline
\end{tabular}

Values of coefficients of Biot in all period in the range from 1 to 20 indicate that the limiting stage of processes is the mixed diffusion.

\section{Summary}

Mathematical processing of isotherms of adsorption of ions of nickel (II) needles of a larch of the Siberian Larix sibirica with use of various models showed that process of adsorption of ions at a temperature of 20 the ${ }^{\circ} \mathrm{C}$ is best of all described by Friendlich's model $(\mathrm{R} 2=0,983)$, and at temperatures of $30^{\circ} \mathrm{C}$ and $40^{\circ} \mathrm{C}$ - the Langmuir model $(\mathrm{R} 2=0,995$ and 0,996 respectively). Values of sorption energy ( $\sim \mathrm{kJ} / \mathrm{mol}$ ) and Gibbs's energy (from-12,6 to-1,6 $\mathrm{kJ} / \mathrm{mol}$ ) on the basis of which process of sorption of ions of $\mathrm{Ni}$ are calculated $^{2+}$ at all three temperatures are carried to processes of physical adsorption, proceeding spontaneously. By a research of kinetics of processes of adsorption of ions of nickel (II) at three temperatures within diffusive model it is revealed that the limiting stage of processes is the mixed diffusion.

\section{Conclusions}

Thus, the possibility of use of Ni (II), dried up biomass of needles of a larch Siberian for sorption extraction of ions, from model solutions is shown by the made experiments. Isotherms of adsorption of the called ions on needles of Larix sibirica are constructed and shortchanging with use of models of Langmuir, Freundlich, Dubinin-Radushkevich and Temkin is made. The calculated values of thermodynamic parameters of adsorption of ions $\mathrm{Ni}(\mathrm{II})$ from water solutions at various temperatures allow referring this process to physical adsorption.

\section{Acknowledgement}

The work is performed according to the Russian Government Program of Competitive Growth of Kazan Federal University.

\section{References}

[1] P. Miretzky, A.F. Cirelli, $\mathrm{Cr}(\mathrm{VI})$ and $\mathrm{Cr}(\mathrm{III})$ removal from aqueous solution by raw and modified lignocellulosic materials: A review, Journal of Hazardous Materials, vol. 180, № 1-3, pp. 1-19, 2010.

[2] V. O. Arief, K. Trilestari, J. Sunarso, N. Indraswati, S. Ismadji, Recent Progress on Biosorption of Heavy Metals from Liquids Using Low Cost Biosorbents: Characterization, Biosorption Parameters and Mechanism Studies, Clean, vol. 36, № 12, pp. 937-962, 2008.

[3] N.A. Khan, S. Ibrahim, P. Subramaniam, Elimination of Heavy Metals from Wastewater Using Agricultural Wastes as Adsorbents, Malaysian Journal of Science, vol. 23, pp. 43-51, 2004.

[4] J. Febrianto, A.N. Kosasih, J. Sunarso, Yi-Hsu Ju, N. Indraswati, S. Ismadji, Equilibrium and kinetic studies in adsorption of heavy metals using biosorbent: A summary of recent studies, Journal of Hazardous Materials, vol. 162, pp. 616-645, 2009.

[5] T.A.H. Nguyen, H.H. Ngo, W.S. Guo, J. Zhang, S. Liang, Q.Y. Yue, Q. Li, T.V. Nguyen, Applicability of agricultural waste and by-products for adsorptive removal of heavy metals from wastewater, Bioresource Technology, vol. 148, pp. 574-585, 2013.

[6] D. S. Malik, C. K. Jain, Anuj K. Yadav, Removal of heavy metals from emerging cellulosic low-cost adsorbents: a review, Applied Water Science, vol. 7, № 5, pp. 2113-2136, 2017.

[7] I. Anastopoulos, M. Karamesouti, A.C. Mitropoulos, G.Z. Kyzas, A review for coffee adsorbents, Journal of Molecular Liquids, vol. 229, pp. 555-565, 2017.

[8] B. Dhir, Potential of biological materials for removing heavy metals from wastewater, Environmental Science and Pollution Research, vol. 21, № 3, ppю 1614-1627, 2014.

[9] R.K. Gautam, A. Mudhoo, G. Lofrano, M.C. Chattopadhyaya, Biomass-derived biosorbents for metal ions sequestration: Adsorbent modification and activation methods and adsorbent regeneration, Journal of Environmental Chemical Engineering, vol. 2, pp. 239$259,2014$.

[10] M.A. Mohammed, A. Shitu, M.A. Tadda, M. Ngabura, Utilization of various agricultural waste materials in the treatment of industrial wastewater containing heavy metals: A Review, International Re- 
search Journal of Environment Sciences, vol. 3, № 3, pp. 62-71, 2014.

[11] S. Gao, T. Luo, Q. Zhou, W. Luo, H. Li, L. Jing, Surface sodium lignosulphonate-immobilized sawdust particle as an efficient adsorbent for capturing $\mathrm{Hg}^{2+}$ from aqueous solution, Journal of Colloid and Interface Science, vol. 517, pp. 9-17, 2018.

[12] S. Demcak, M. Balintova, M. Hurakova, M.V. Frontasyeva , I. Zinicovscaia, N. Yushin, Utilization of poplar wood sawdust for heavy metals removal from model solutions, Nova Biotechnologica et Chimica, vol. 16, № 1, pp 26-31, 2017.

[13] Çakir E., Tosunoğlu V., Boncukcuoğlu R., Korkmaz M., Fil B.A. Kinetic and Fixed Bed Studies for Copper Removal from Solutions by Walnut Tree Sawdust (Juglans regia Linnaeus), Global NEST Journal, vol 19, № 2, pp. 327-335, 2017.

[14] V.N. Losev, E.V. Elsufiev, O.V. Buyko, A.K. Trofimchuk, R.V. Horda, O.V. Legenchuk, Extraction of precious metals from industrial solutions by the pine (Pinus sylvestris) sawdust-based biosorbent modified with thiourea groups, $\underline{\text { Hydrometallurgy, vol. } 176}$, pp. 118-128, 2018.

[15] Y. Bulut, Z. Tez, Removal of heavy metals from aqueous solution by sawdust adsorption, Journal of Environmental Sciences, vol. 19 pp. 160-166, 2007.

[16] B. Das, Response surface modeling of copper (II) adsorption from aqueous solution onto neem (Azadirachta indica) bark powder: Central composite design approach, Journal of Materials and Environmental Sciences, vol. 8, № 7, pp. 2442-2454, 2017.

[17] A. Sen, H. Pereira, M. A. Olivella, I. Villaescusa, Heavy metals removal in aqueous environments using bark as a biosorbent, International Journal of Environmental Science and Technology, vol. 12, pp. 391-404, 2015.

[18] D.D. Fazullin, D.A. Kharlyamov, G.V. Mavrin, A.A. Alekseeva, S.V. Stepanova, I.G. Shaikhiev, A.S. Shaimardanova, The use of leaves of different tree species as a sorption material for extraction of heavy metal ions from aqueous media, International Journal of Pharmacy and Technology, vol. 8, № 2, pp. 14375-14391, 2016.

[19] J. Zolgharnein, M. Bagtash, S. Feshki, P. Zolgharnein, D. Hammond, Crossed mixture process design optimization and adsorption characterization of multi-metal ( $\mathrm{Cu}$ (II), $\mathrm{Zn}$ (II) and $\mathrm{Ni}$ (II)) removal by modified Buxus sempervirens tree leaves, Journal of the Taiwan Institute of Chemical Engineers, vol. 78, pp. 104-117, 2017.

[20] S. Kuppusamy, P. Thavamani, M. Megharaj, K. Venkateswarlu, Y.B. Lee, R. Naidu, Oak (Quercus robur) Acorn Peel as a LowCost Adsorbent for Hexavalent Chromium Removal from Aquatic Ecosystems and Industrial Effluents, Water, Air \& Soil Pollution, vol. 227, № 62, 11 p., 2016.

[21] Vaghetti, J. C., Lima, E. C., Royer, B., Brasil, J. L., da Cunha, B. M., Simon, N. M., Cardoso, N. F., Noreña, C. P. Z., Application of Brazilian-pine fruit coat as a biosorbent to removal of $\mathrm{Cr}$ (VI) from aqueous solution-kinetics and equilibrium study, Biochemical Engineering Journal, vol. 42, pp. 67-76, 2008

[22] P.P. Ndibewu, R.L. Mnisi, S.N. Mokgalaka, R.I. McCrindle, Heavy metal removal in aqueous systems using Moringa oleifera: A Review, Journal of Materials Science and Engineering, vol. 1, № 6 , pp. 143-153, 2011.

[23] H.S. Altundoğan, A. Topdemir, M. Çakmak, N. Bahar, Hardness removal from waters by using citric acid modified pine cone, Journal of the Taiwan Institute of Chemical Engineers, vol. $58, \mathrm{pp}$. 219-225, 2016.

[24] C. Kütahyali, Ș. Sert, B. Çetinkaya, S. Inan, M. Eral, Factors Affecting Lanthanum and Cerium Biosorption on Pinus brutia Leaf Powder, Separation Science and Technology, vol. 45, № 10, pp. 1456-1462, 2010.

[25] M. Dakiky, M. Khamis, A. Manassra, M. Mer'eb, Selective adsorption of chromium(VI) in industrial wastewater using low-cost abundantly available adsorbents, Advances in Environmental Research, vol. 6, № 4, pp. 533-540, 2002.

[26] H. Serencam, A. Gundogdu, Y. Uygur, B. Kemer, V.N. Bulut, C. Duran, M. Soylak, M. Tufekci, Removal of cadmium from aqueous solution by Nordmann fir (Abies nordmanniana (Stev.) Spach. Subsp. nordmanniana) leaves, Bioresource Technology, vol. 99, pp. 1992-2000, 2008.

[27] M. Aoyama, T. Sugiyama, S. Doi, N.-S Cho, H.-E. Kim, Removal of Hexavalent Chromium from Dilute Aqueous Solution by Coniferous Leaves, Holzforschung, vol. 53, № 4, pp. 365-368, 2005.

[28] N.S. Cho, M. Aoyama, K. Seki, N. Hayashi, S. Doi, Adsorption by coniferous leaves of chromium ions from effluent, Journal of Wood Science, vol. 45, pp. 266-270, 1999.
[29] T.R. Denisova, R.Z. Galimova, I.G. Shaikhiev, G.V. Mavrin, Re search Journal of Pharmaceutical, Biological and Chemical Sciences, 7, 5, 1765-1771 (2016). 